$13^{\text {th }}$ International Conference on

\title{
Experimental Investigation of the Effect of Vibration During Tillage Process of Multi Shank Plough Blade
}

\author{
M. A. Awad-Allah", H. M. Mahgoub*, M. E. Abo-Elnor ${ }^{*}$, M. A. Shahin ${ }^{* *}$
}

Abstract: The motion of plough during a quasi-static tillage process is opposed by a high tillage resistance that typically limits the cutting depth to $30 \mathrm{~cm}$. This study experimentally investigates the effects of the blade geometry and operating conditions on the draft force during tillage. Scaled V-multi-shank ploughs with three different blade angles are examined at different soil types, tillage speeds and cutting depths. Tests are repeated with an added plough vibratory motion at various frequencies and amplitudes.

Blade vibration during the tillage process is found to have a considerable effect in reducing the tillage resistance. This effect may occasionally lead to overcoming the resistance at operating conditions where the driving mechanism without vibration could not match the tillage requirements. Results show that tillage depth, tillage velocity and blade angle all have direct and proportional effects on the tillage resistance force. Vibration frequency and amplitude on the other hand, reflect in desirable inverse and proportional effects.

Keywords: Dynamic modeling, Soil-tool interaction, Vibratory tillage

\section{Introduction}

In soil-tool interaction, soil reaction and deformation mechanisms depend on the design and geometry of the tool, soil characteristics, soil-tool interrelations and many operational parameters. Analysis of such interaction involves a number of uncertain and complicated phenomena. Despite the potential of the forced vibration as a promising mean for soil pulverization and reducing the draft force and machine weight, it has not yet been considered as a practical method in tillage processes. This is mainly attributed to the limited qualitative knowledge of the effects of different operating parameters on the performance of the tillage tool.

Many recent investigations of the vibration effects have been motivated by the increased possibilities of applying engineered vibration. Yow and Smith [1] analyzed one dimensional sinusoidal vibratory tillage and found that the tillage force decreases at the same cutting depth and velocity compared to conventional methods. The maximum force reduction was obtained at velocity ratios (tool velocity/carriage velocity) between 1.5 and 3.0. They concluded that this range should be appropriately observed in practical applications in order to minimize the extra drive power.

\footnotetext{
*** Egyptian Armed Forces

** Modern Academy
} 
Spektor and Katz [2] experimentally studied the frontal resistance forces in soil cutting with emphasis on their dependence on tool displacement during the loading and unloading stages under quasi-static and dynamic regimes. Reported results showed that under a dynamic cutting regime, the frontal resistance force increases steeply at the onset of the loading stage, over a relatively narrow interval of the tool displacement. This is attributable to the combined influence of the inertia, viscosity, and internal friction of the soil.

Niyamapa and Salokhe [3] experimentally studied the failure and disturbance of sandy loam soil under vibratory tillage tools in a soil bin. They observed a brittle failure of the soil under simple vibratory tillage tool. The failure area was generally of crescent shape with cracks in radial and transverse directions. The amount of soil fragments in the crescent shaped failure zone increased with the tool oscillating frequency, The size of soil fragments was found to be a function of the velocity ratio.

Other experiments were conducted $\mathrm{n}$ a soil bin by Niyamapa and Salokhe [4]. The objective was to study the force requirement and pressure distribution under the vibratory tillage tools. Reported results showed that at travel speed of $0.224 \mathrm{~m} / \mathrm{s}$ and oscillating frequencies between 9.8 to $15.6 \mathrm{~Hz}$, the horizontal force decreased to 0.66 to 0.52 of its values without vibration. The vertical force ratio also decreased from 0.44 to 0.25 which indicate the positive proportional effect of the oscillating frequency increase.

Tanya Niyamapa and Salokhe [5] carried out an experimental investigation on vibrating tillage tools and sandy loam soil. They concluded that the values of dry bulk density tended to increase with oscillating frequency. It increased by about 5.3 to $13.8 \%$ at the frequency of $8.7 \mathrm{~Hz}$ and by 17 to $20 \%$ at the frequency of $13.9 \mathrm{~Hz}$ and by $5 \%$ at no vibration. On the other hand, it slightly decreased when the oscillating amplitude was increased from 59 to $77 \mathrm{~mm}$.

A three-dimensional dynamic finite element analysis was carried out by Abo-Elnor [6] to simulate soil-tool interaction and study the effect of cutting speed and cutting acceleration on the cutting force. Results proved the significant effect of the cutting acceleration and the insignificant effect of the cutting speed.

A series of vibro-cutting tests were executed by Muro and Tran [7] on tuffaceous rock sample at various combinations of frequencies (from 0 to $70 \mathrm{~Hz}$ ), amplitudes of vibration (from 0.07 to $1.06 \mathrm{~cm}$ ) and cutting velocities (from 0.35 to $0.95 \mathrm{~cm} / \mathrm{s}$ ) with fixed cutting depth of $0.8 \mathrm{~cm}$ and rake angle $9 \mathrm{rad}$. Results showed that the excavation force decreases with vibro-cutting compared to the non-vibration cutting, an effect which slightly increases as the cutting velocity increases. The ratio of maximum excavation force with vibrocutting to that of non-vibration was found to decrease hyperbolically with the frequency of vibration at fixed amplitudes.

The previous studies prove that tillage vibration could effectively reduce draft force. Cutting depth, in addition to cutting tool velocity and geometry must all be considered in order to achieve best results. Most previous investigations focused on the application of vibration to narrow cutting tools and did not consider the accumulated soil in front of wide or v-type blades. This experimental study is an attempt to investigate the effects of tillage vibration, blade geometry and operating conditions on the tillage draft force of a multishank v-type plough. 


\section{Experimental Setup}

The purpose of the experimental work is to investigate the dynamics of single and multiple tines at different cutting speeds and depths with and without an added vibratory motion. Specially made tines resembling real ploughs (with scale 1:10) are used. These models have different blade angles and are examined at various operating conditions. The effects of an added vibratory motion, with different frequencies and amplitudes, on the plough dynamics are also studied. Moreover, the complete experimental program is repeated with two different types of soil.

The platform was designed and constructed at the department of Mechanical Equipment, Military Technical College, during the first phase of this work. The soil bin was equipped with the necessary motion mechanisms and traction power unit. Control and measuring devices were later added, and the required acquisition software was then developed.

\section{Construction of the Test Rig}

The laboratory test rig consists of the following main parts as shown in figure (1)

1- soil bin

3- multi shank plough blades

5- plough vibration mechanism

7- data acquisition system
2- plough model

4- carriage driving mechanism

6- speed control units

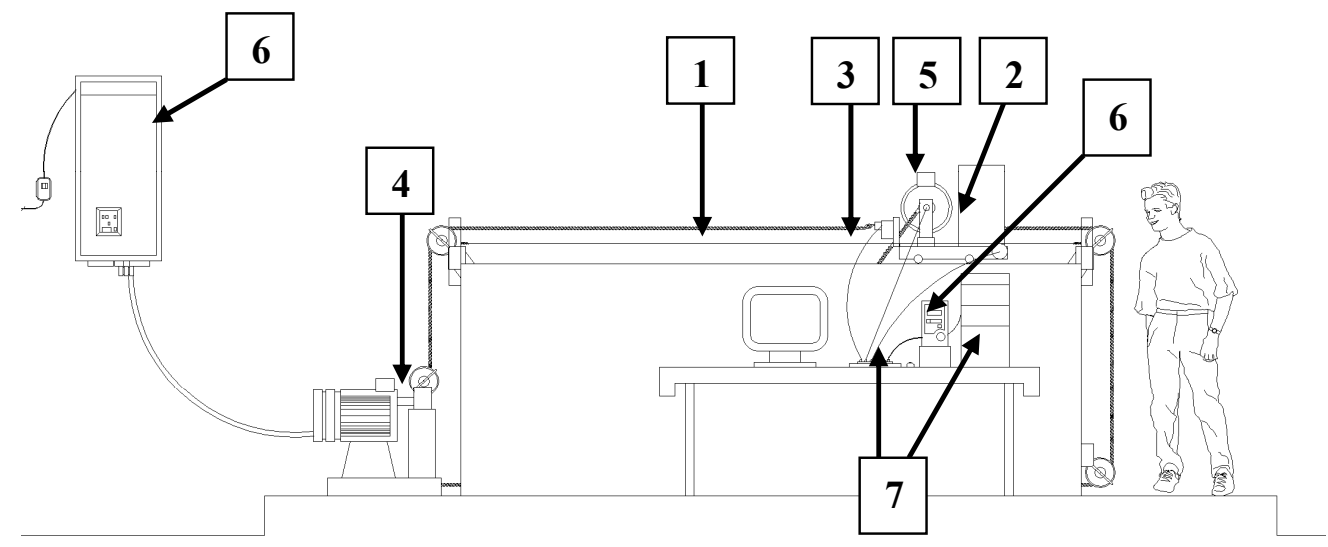

Fig. 1 Schematic of the test rig construction.

Table (1) shows the main design and operational parameters assessed. Each parameter was changed within the range prescribed in the table, resulting in hundreds of combinations. The experimental investigations were conducted at each case. 
Table (1) Operating parameters.

\begin{tabular}{c||c|c|c|c|c}
\hline \hline \multirow{2}{*}{ Soil type } & $\begin{array}{c}\text { Blade } \\
\text { angle }\end{array}$ & $\begin{array}{c}\text { Depth } \\
\text { of cut }\end{array}$ & Amplitude & Frequency & $\begin{array}{c}\text { Motor controller } \\
\text { Frequency }\end{array}$ \\
\cline { 2 - 6 } & $\left(\boldsymbol{\mu}^{\circ}\right)$ & $\mathbf{( m )}$ & $\mathbf{( m )}$ & $\mathbf{( r p m )}$ & $\mathbf{( H z )}$ \\
\hline \hline 1 & 100 & 0.01 & 0.000 & 0.00 & 6 \\
\hline 2 & 110 & 0.02 & 0.002 & 300 & 8 \\
\hline--- & 120 & 0.04 & 0.004 & 600 & 10 \\
\hline---- & ---- & ---- & 0.008 & 900 & --- \\
\hline \hline
\end{tabular}

\section{Soil parameters}

A medium well graded sand soil is used. The following Tables $(1,2)$ present the used soils parameters [8].

Table (2) Properties of soil 1.

\begin{tabular}{c||c|c|c|c|c|c|c|c|c|c|c}
\hline \hline $\begin{array}{c}\text { Soil } \\
\text { parameters }\end{array}$ & Aa & Ad & $\mathrm{Ca}$ & $\mathrm{Co}$ & $\mathrm{C}$ & $\delta$ & $\beta$ & $\varphi_{0}$ & $\varphi$ & $\gamma_{0}$ & $\gamma$ \\
\cline { 2 - 10 } & $\mathrm{N} / \mathrm{m}^{2}$ & & $\mathrm{~N} / \mathrm{m}^{2}$ & $\mathrm{~N} / \mathrm{m}^{2}$ & deg. & $\mathrm{deg}$ & $\mathrm{deg}$ & $\mathrm{deg}$ & $\mathrm{N} / \mathrm{m}^{3}$ & $\mathrm{~N} / \mathrm{m}^{3}$ \\
\hline \hline value & 3.3 & 0 & .335 & 0 & 0 & 18.5 & 59 & 25 & 28 & 17500 & 16500 \\
\hline \hline
\end{tabular}

Table (3) Properties of soil 2.

\begin{tabular}{c||c|c|c|c|c|c|c|c|c|c|c}
\hline \hline $\begin{array}{c}\text { Soil } \\
\text { parameters }\end{array}$ & $\mathrm{Aa}$ & $\mathrm{Ad}$ & $\mathrm{Ca}$ & $\mathrm{Co}$ & $\mathrm{C}$ & $\delta$ & $\beta$ & $\varphi_{0}$ & $\varphi$ & $\gamma_{0}$ & $\gamma$ \\
\hline \hline value & 3.3 & 0 & .324 & 0 & 0 & 18 & 58 & 25 & 27 & 16500 & 15800 \\
\hline \hline
\end{tabular}

\section{Plough Vibration Mechanism}

The vibrating unit consists of three main parts as shown in figure (2):

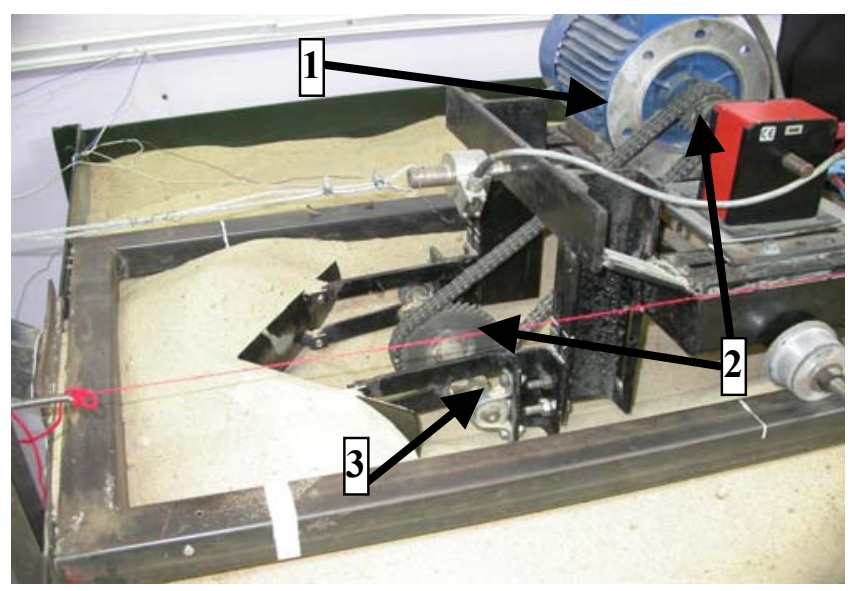

Fig. 2 Plough vibration mechanism. 


\section{(1) Driving motor}

The driving motor is a 3-phase electrical motor with delta $(\Delta)$ arrangement.

\section{(2) Driver and driven sprockets}

The driver and driven sprockets are used to transfer the motion from the driving motor to an eccentric shaft through a chain. The drive sprocket connected to the motor axis has 19 teeth and the driven sprocket connected to the eccentric shaft has 38 teeth. This arrangement reduces the output speed and duplicates the output torque. This shaft is coaxially supported to the carriage and its eccentric part is housed in a special bearing fixed to the cutting blade. This insures that shaft rotation will cause the carriage to oscillate with frequency and amplitude depending on the shaft speed and eccentricity.

\section{(3) The eccentric shaft}

Three shafts with different eccentricities (namely 1, 2 and $4 \mathrm{~mm}$ ) as shown in figure (3) were specially manufactured for this purpose. The vibration frequency was changed by varying the drive motor speed.

\section{(4) Force detecting sensor}

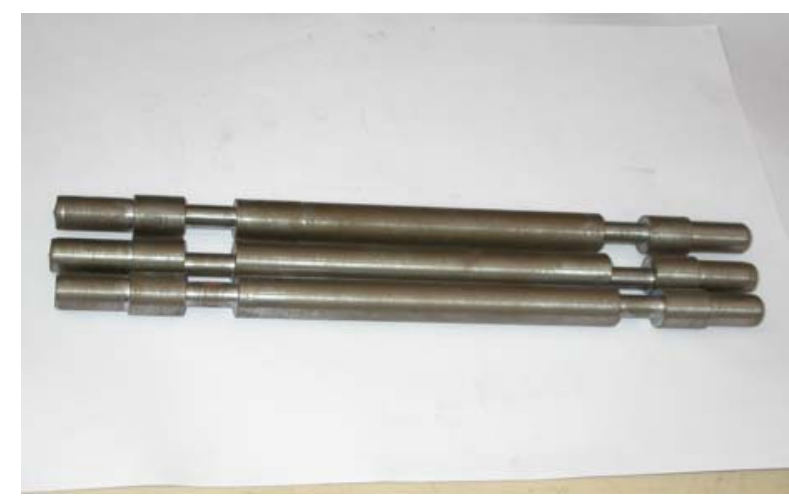

Fig. 3 The eccentric shafts.

The main job of the system is to measure the tillage force. For this reason the blade is connected to the moving chassis which is connected to load cell which is represent the force sensor as shown in figure (4)

\section{(5) Tacho generator}

Taco generator is connected to the motor of the vibrating mechanism in order to measure the rpm of the motor during tillage process and gives an indication about the tillage resistance force acts on the blade at vibrating state as shown in figure (5).

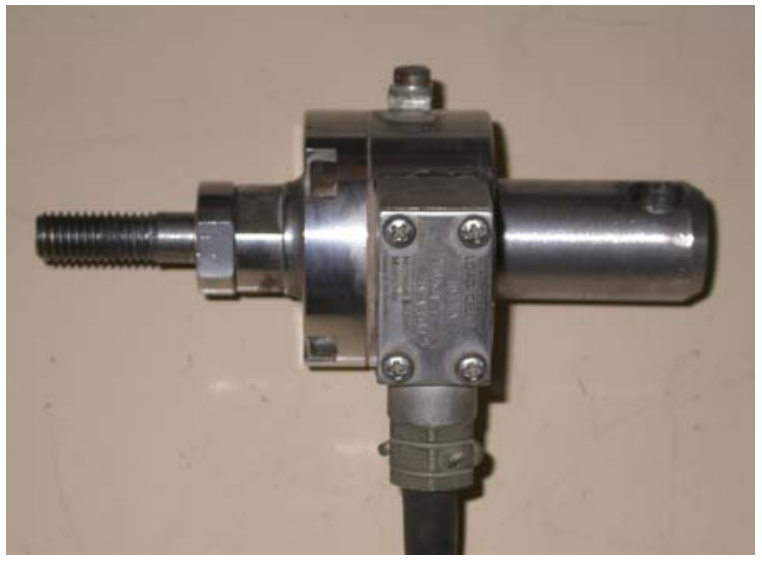

Fig. 4 Force detecting sensor.

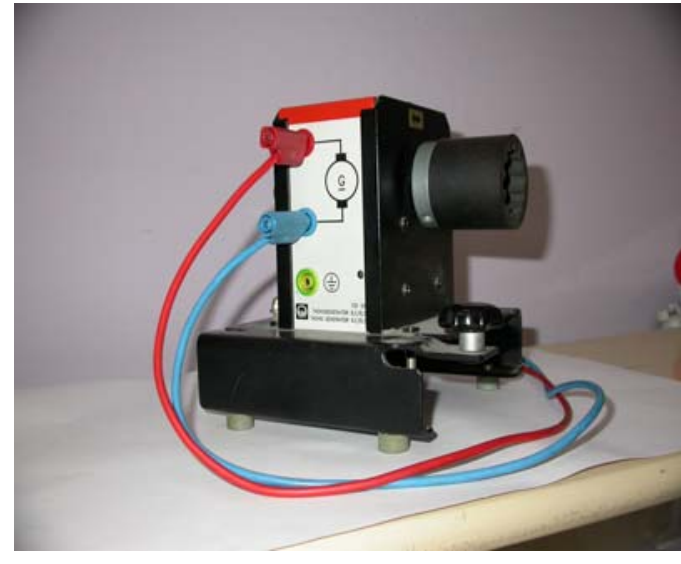

Fig. 5 Tacho generator. 


\section{6) Position displacement sensor}

It is connected to the moving chassis equipped with pulley fixed to the rotating button and this pulley connected to the two ends of the soil bin by a rope tightens by two springs at the ends. It used to measure the position of the carriage during cutting process also to indicate the resistance force acts on the blade at vibrating and nonvibrating state as shown in figure (6). The position displacement sensor consists of a potentiometer with $20 \mathrm{~K} \Omega$ variable resistance which is varying according to the rotation of the button connected to the Pulley according to the position of the carriage.

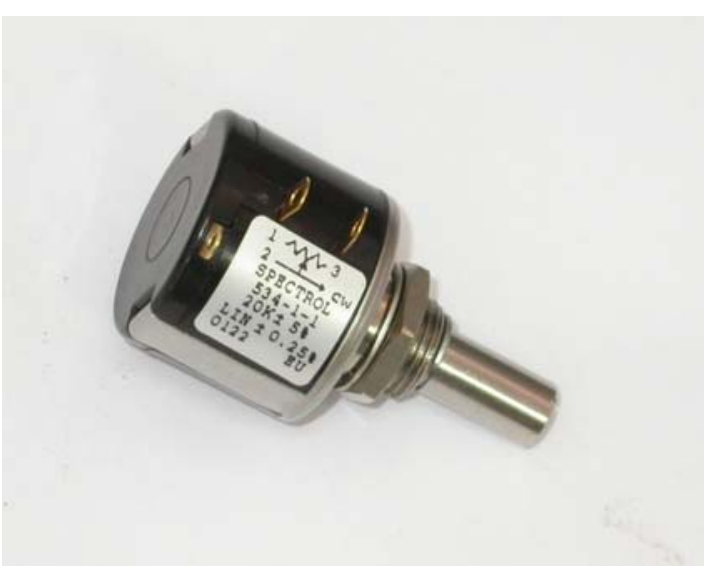

Fig. 6 Position displacement sensor.

\section{Data Acquisition System}

A complete data acquisition system is used for acquiring data from all transducers with suitable sampling frequency (100 samples per second) over the period of each test. Measured is carried out with standard National Instruments Data Acquisition Card and using Industrial Standard LabVIEW software. After each test, measured data are stored on the computer disk for analysis and manipulation. The setup, figure (7), consists of the following main parts:

1- NI DAQ 6033E series

2- Terminal Block and Strain Gauge Conditioning Unit NI-SC2043

3- Cable

4- External DC power supply

5- Computer (PC-monitor-key board-mouse)

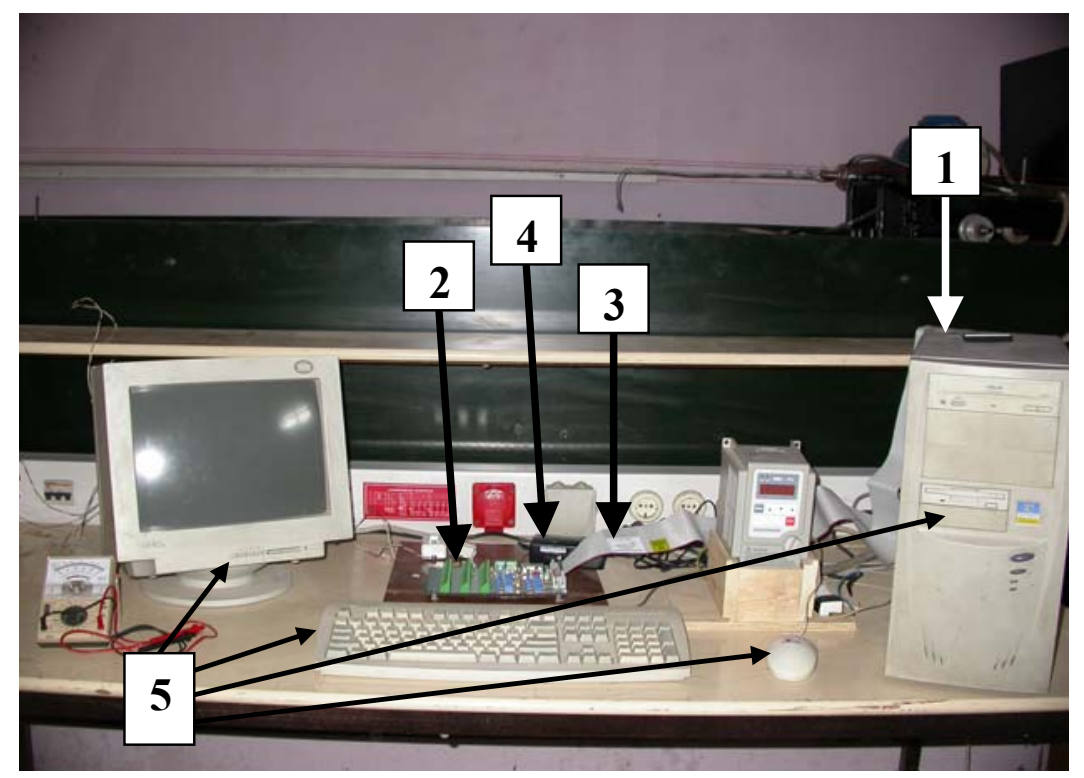

Fig. 7 Data acquisition system. 
Figure (8) schematically shows the measuring setup with the data acquisition system and the flow of control and measured signals during experimentation.

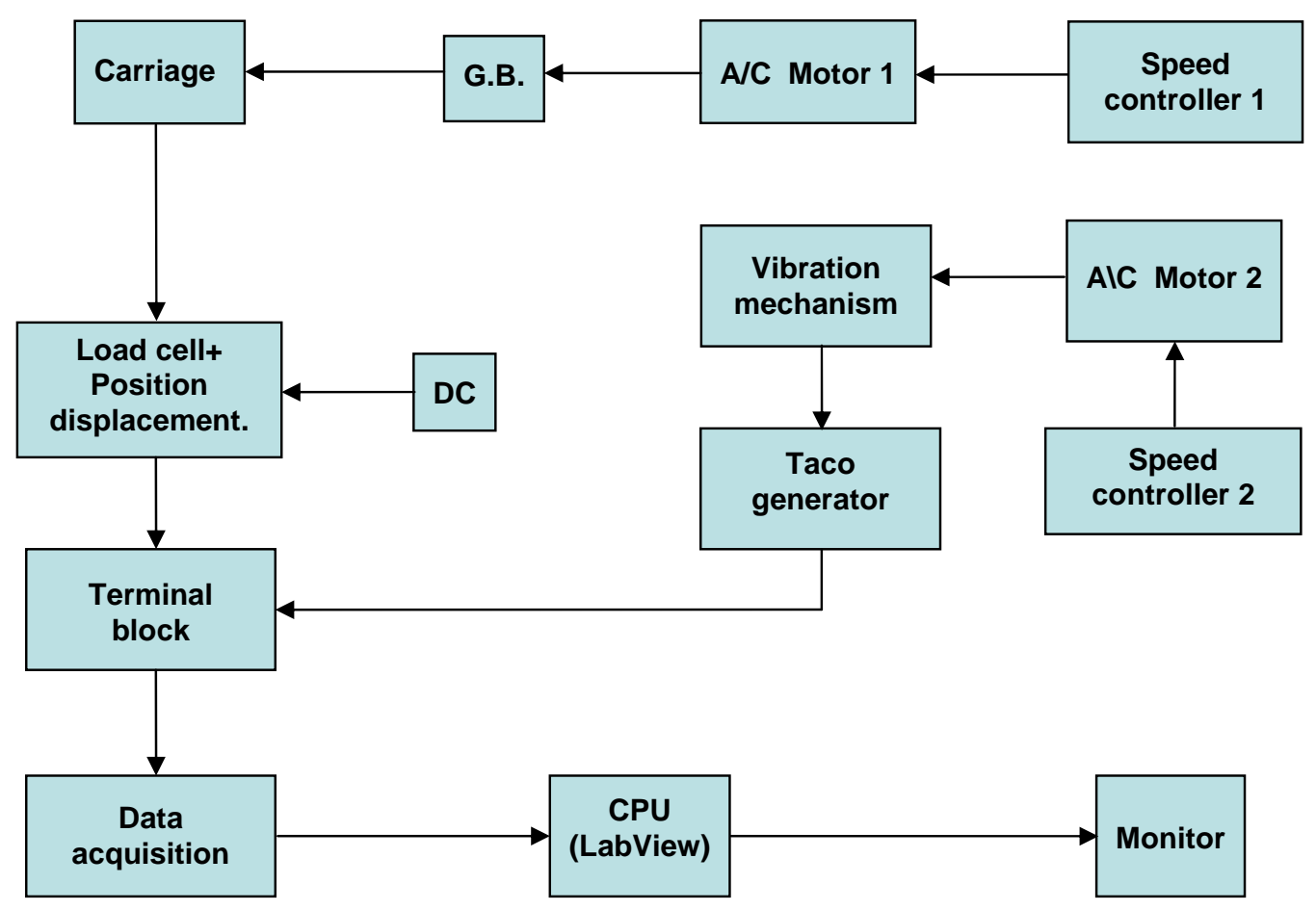

Fig. 8 Signal flow chart.

\section{Primary Measurements}

The carriage accelerates at the beginning then moves steadily for the rest of each test. The tacho speed seems to have nearly a constant value during the carriage steady motion. The towing force increases sharply at the beginning of each test then converges to a steady value. The current study focuses on the steady part of the movement and the accompanying average velocity and towing force. Figure (9) shows the measured data plotted against reading time for a sample test.

As the tillage is operated, the soil is accumulated in front of the blade forming a prism. The steady state movement is reached only after the full prism is formed accompanied by a considerable soil spilling. Experimental data showed that this is achieved after the carriage motion covers nearly $0.7 \mathrm{~m}$ and continues until the carriage is stopped near the end of the total stroke which is nearly $2.5 \mathrm{~m}$. 


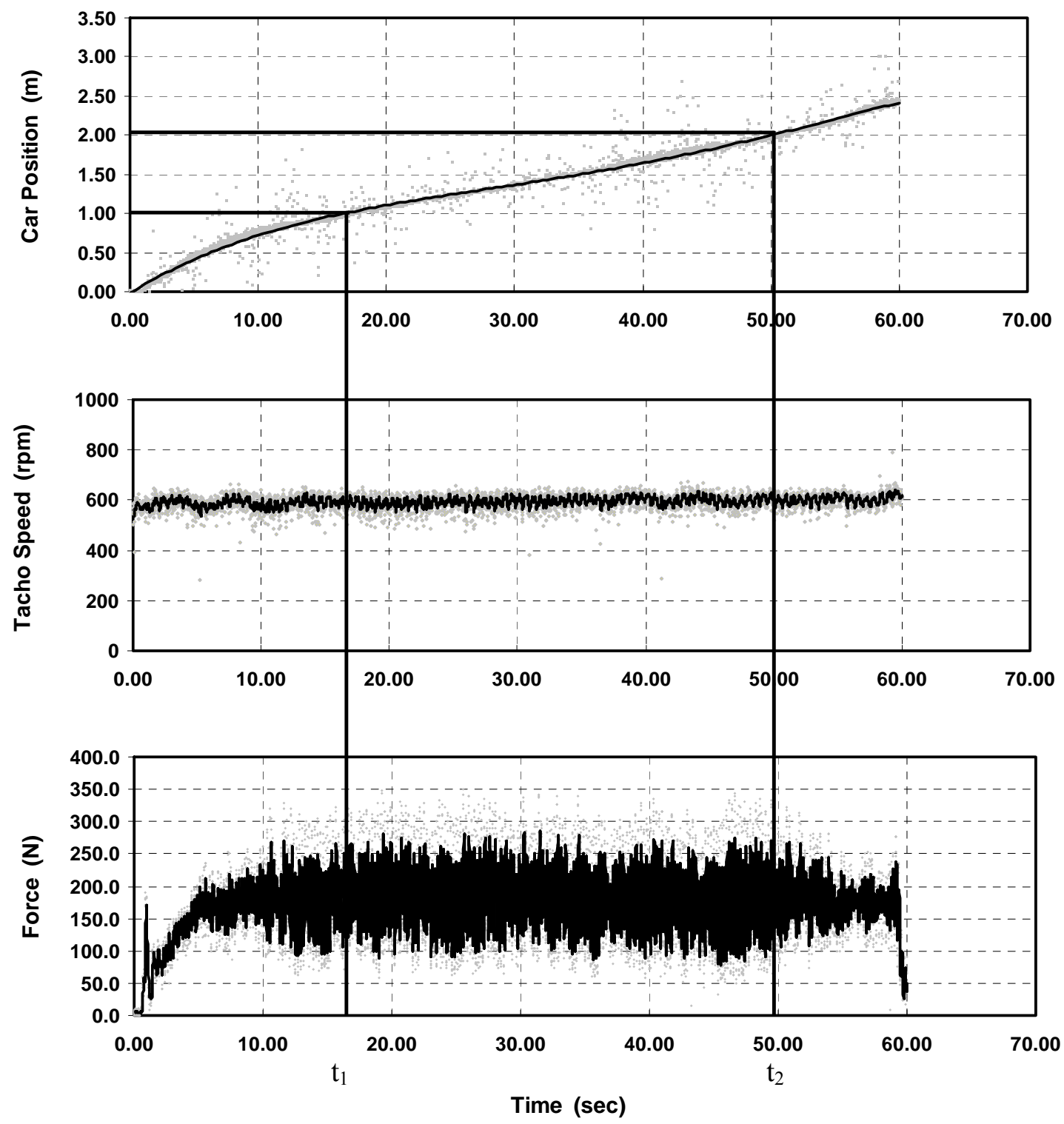

Fig. 9 Measured force, Tacho speed and carriage position.

Test name: test_201.lvm.

$\begin{array}{llll}\text { Soil : } & 1 & \text { Sp. Controller Freq. (HZ): } & 6 \\ \text { Cutting Angle (deg) : } & 120 & \text { Vibration Amp. (m): } & 0.004 \\ \text { Cutting Depth (m): } & 0.04 & \text { Tacho speed (rpm): } & 600\end{array}$

The figure shows that the cutting resistance increases until a cut pile is accumulated in front of the tillage tool, then a steady state resistance is accomplished, which indicates a further movement of the tillage tool without significant increase in the cutting resistance. 
The average speed and tillage force were thus evaluated from the data measured between the points at which the stroke reaches $1 \mathrm{~m}$ and $2 \mathrm{~m}$ respectively.

Therefore, the average traction speed and force were calculated as follows:

$$
\begin{aligned}
& V_{\text {average }}=\frac{1}{i_{2}-i_{1}+1} \cdot \sum_{i_{1}}^{i_{2}} v_{i} \\
& F_{\text {average }}=\frac{1}{i_{2}-i_{1}+1} \cdot \sum_{i_{1}}^{i_{2}} F_{i}
\end{aligned}
$$

where

$V_{\text {average }}$ the average carriage velocity

$F_{\text {average }}$ average driving force,

$v_{i}, F_{i}$ instantaneous readings of velocity and force at instant $\mathrm{i}$,

$i_{1} \quad$ Reading number at time $t_{1}$

$i_{2} \quad$ Reading number at time $t_{2}$

$t_{1}, t_{2}$ Times at which carriage travel reaches $1 \mathrm{~m}$ and $2 \mathrm{~m}$ respectively.

The average speed and tillage force were evaluated for 540 tests conducted with 2 types of soil and different blade geometries, operating parameters with and without vibratory motion.

\section{Grouping of Results}

In order to investigate the effect of different operating conditions on the performance parameters, the carriage velocity is plotted against the driving force in each set of experiments. Figures (10 to 12) show the experimental results obtained with the first soil and tillage tool with blade angle $120^{\circ}$. The results are grouped according to tillage depth and shaking amplitude. Apart from the no shaking condition, each graph shows three plots (3 point each) at constant shaking frequency. The three figures exhibit the effect of all working conditions on the performance parameters, i.e. the net results of 90 experiments.

The trends are similar and prove the positive effect of shaking the tool with various frequencies and amplitudes. 


\section{Tillage depth $=10 \mathrm{~mm}$}

Blade

Shaking

Amplitude

$0 \mathrm{~mm}$

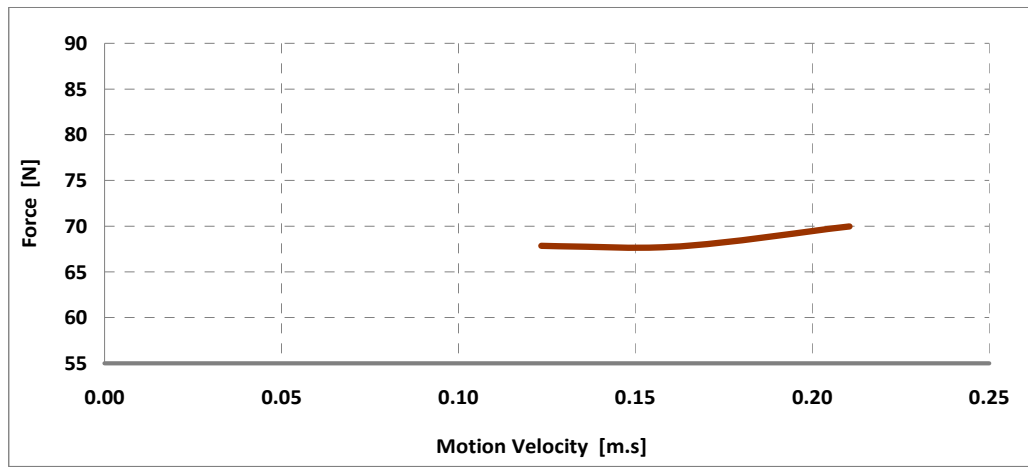

$2 \mathrm{~mm}$

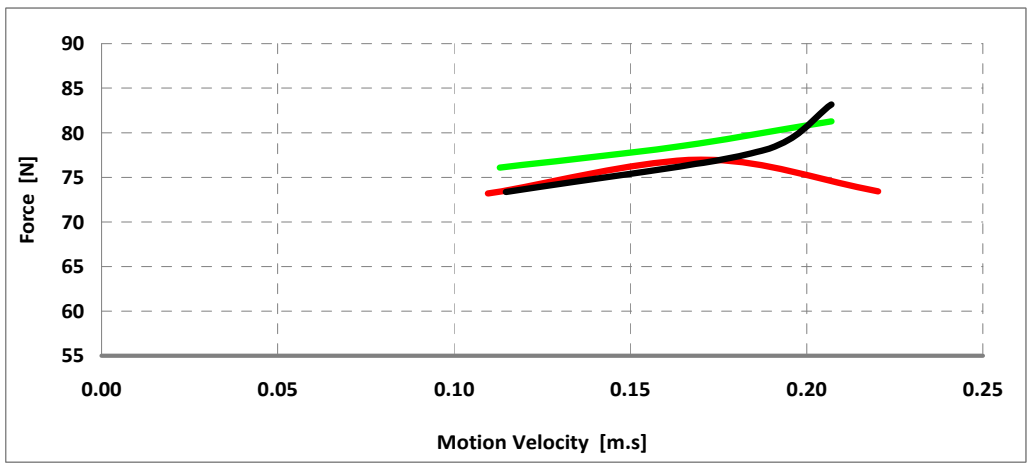

$4 \mathrm{~mm}$

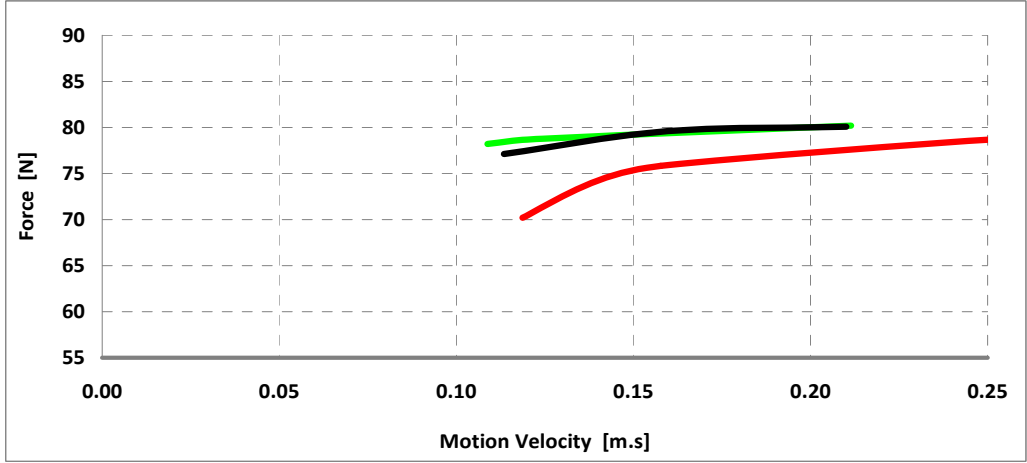

8

$\mathrm{mm}$

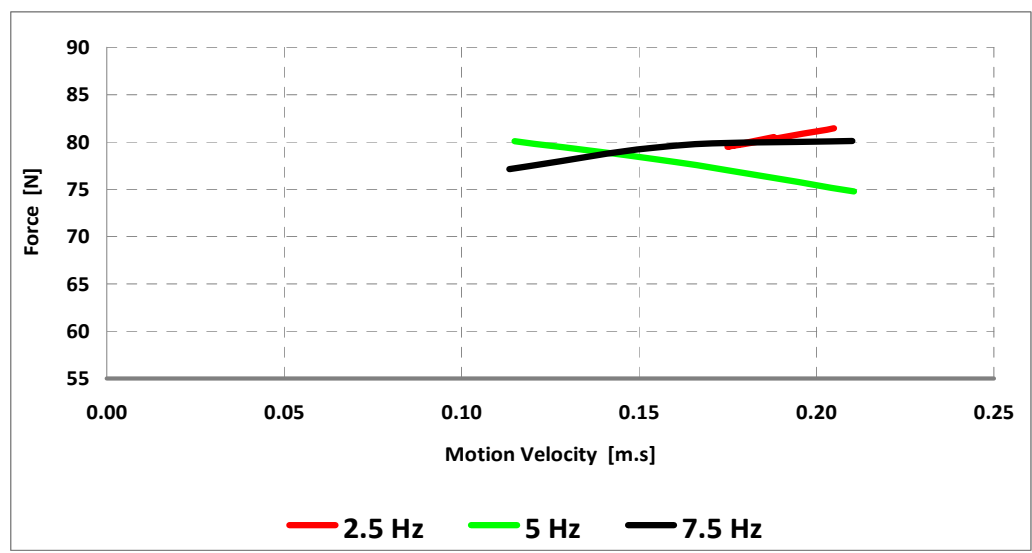

Fig. 10 Soil 1 - Blade angle 120 deg. 


\section{Tillage depth $=20 \mathrm{~mm}$}

Blade

Shaking

Amplitude

$0 \mathrm{~mm}$

$2 \mathrm{~mm}$
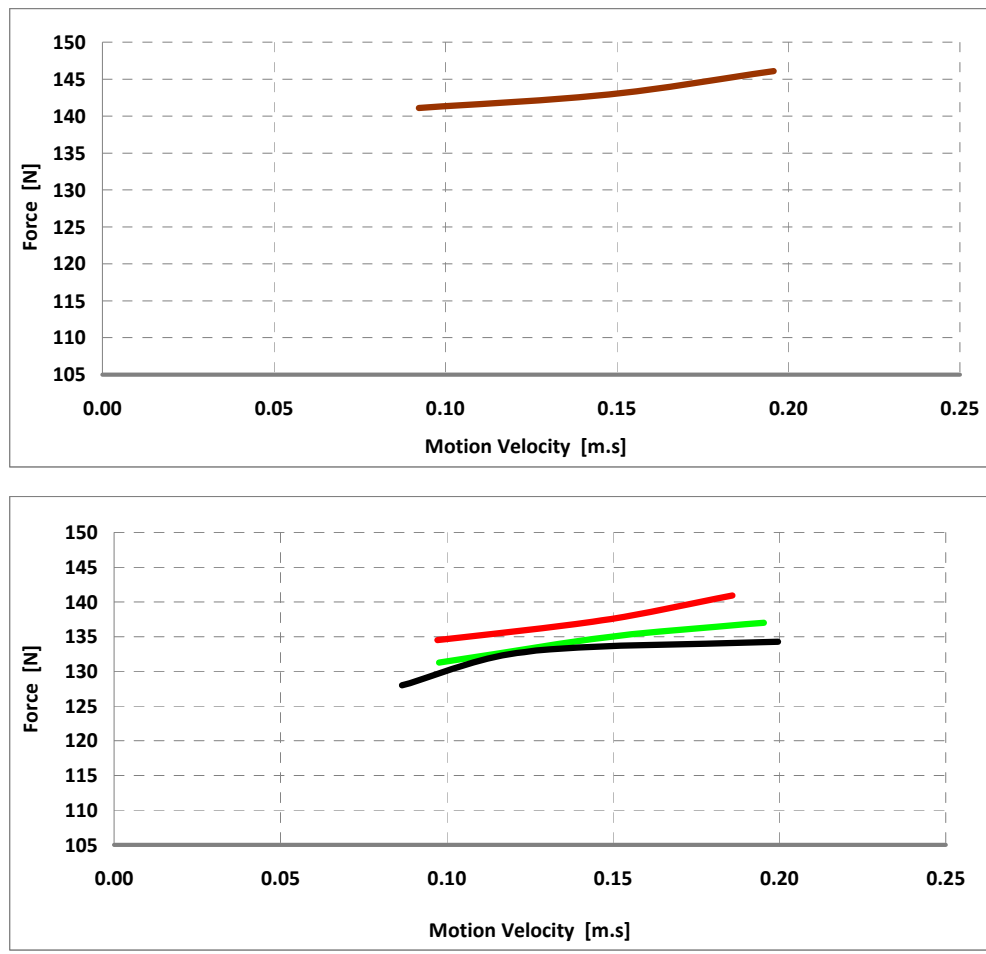

$4 \mathrm{~mm}$

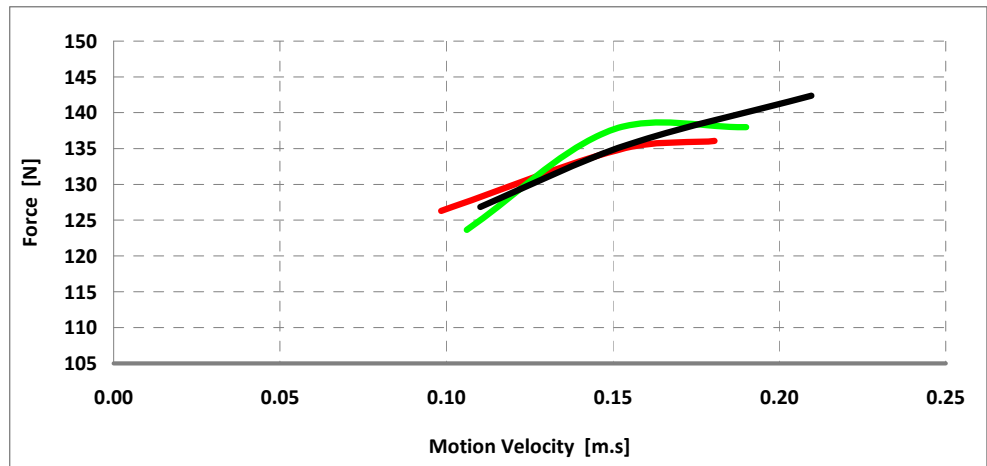

$8 \mathrm{~mm}$

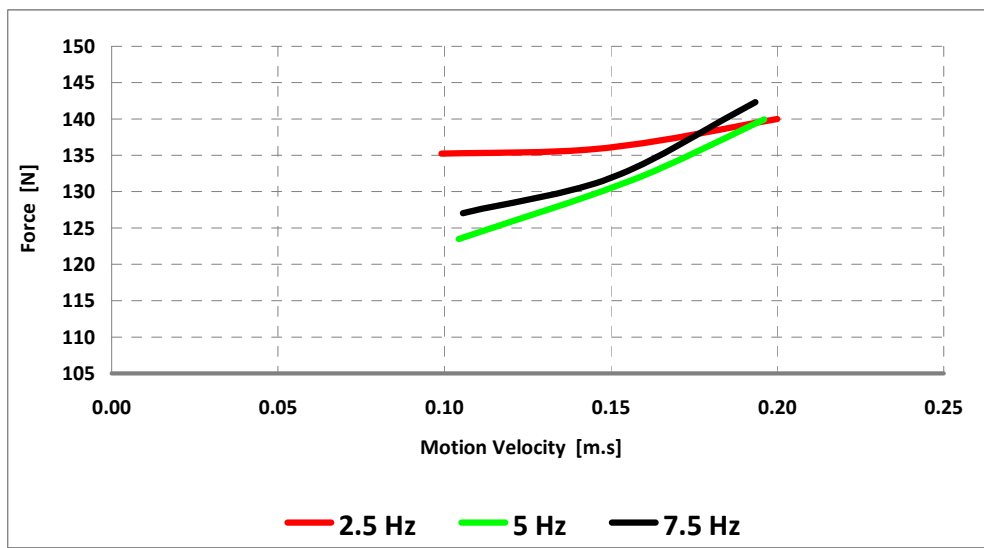

Fig. 11 Soil 1 - Blade angle 120 deg. 


\section{Tillage depth $=40 \mathrm{~mm}$}

Blade

Shaking amplitude

$0 \mathrm{~mm}$

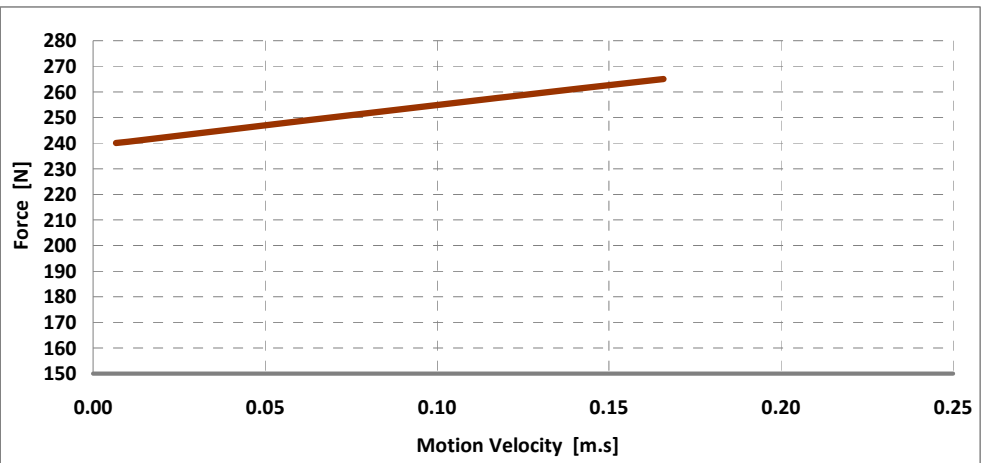

r mm

$4 \mathrm{~mm}$
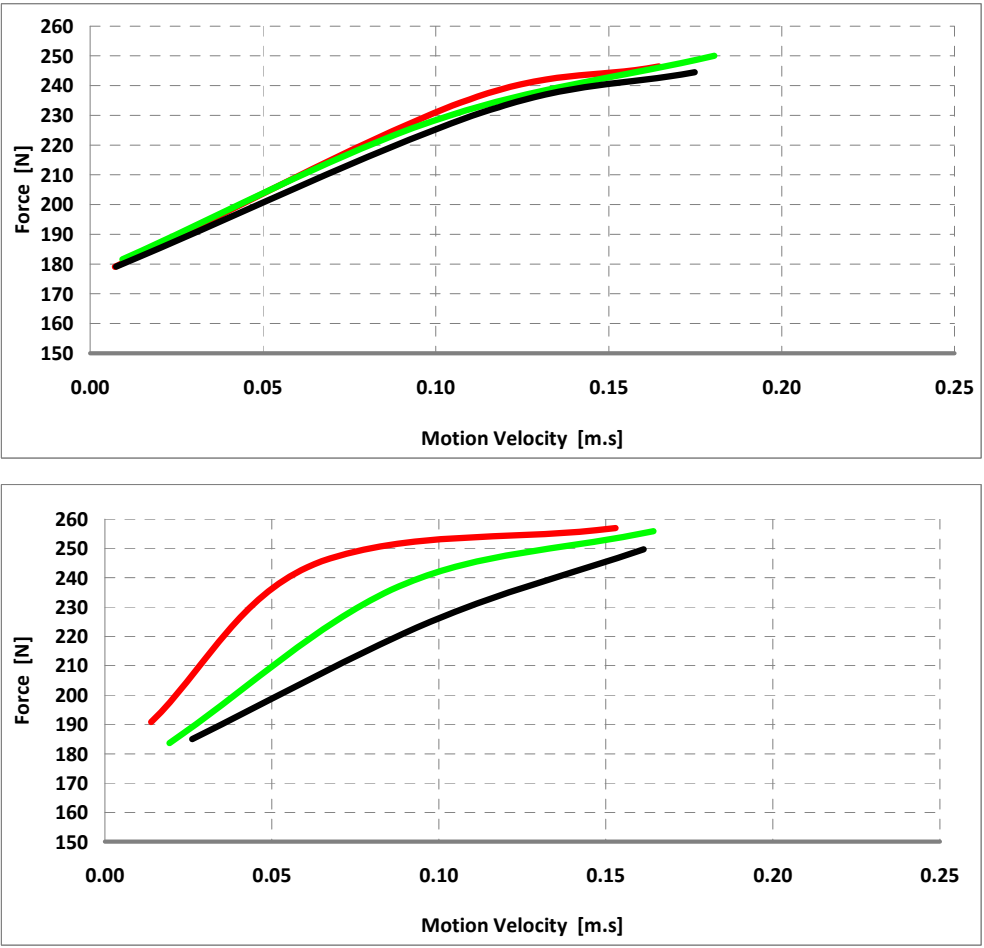

$8 \mathrm{~mm}$

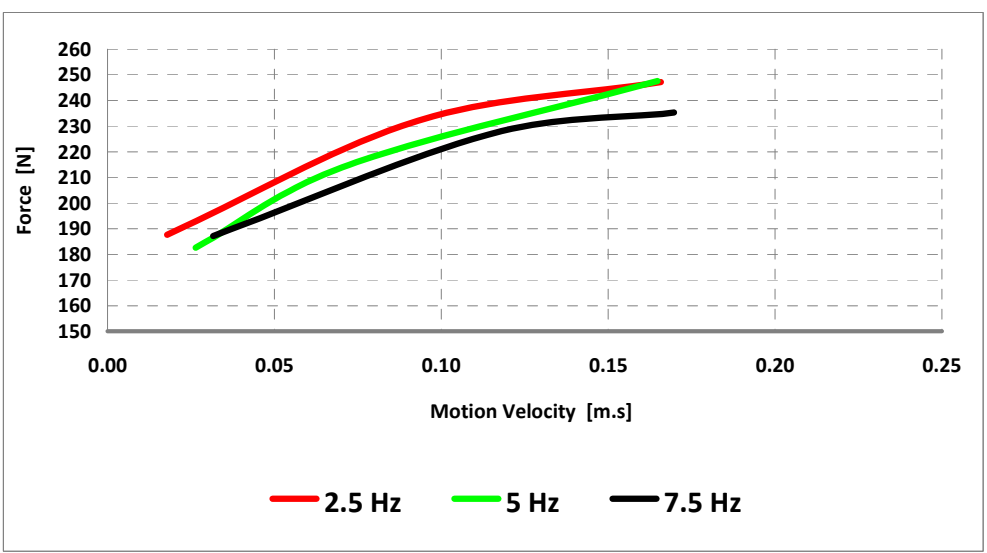

Fig. 12 Soil 1 - Blade angle 120 deg. 


\section{Influence of Operating Parameters on Draft Force with and without Vibratory Tillage}

\section{Effect of Tillage Depth}

Figure (13) shows that, as the tillage depth is increased, the needed draft forces increases.

The application of vibration results in less needed force. This becomes more apparent as the cutting depth increases. However, at the shallow depth $(0.01 \mathrm{~m})$, the effect of vibration is negligible due to the low resistance of the soil and the need to overcome the inertia force of the blade masses.

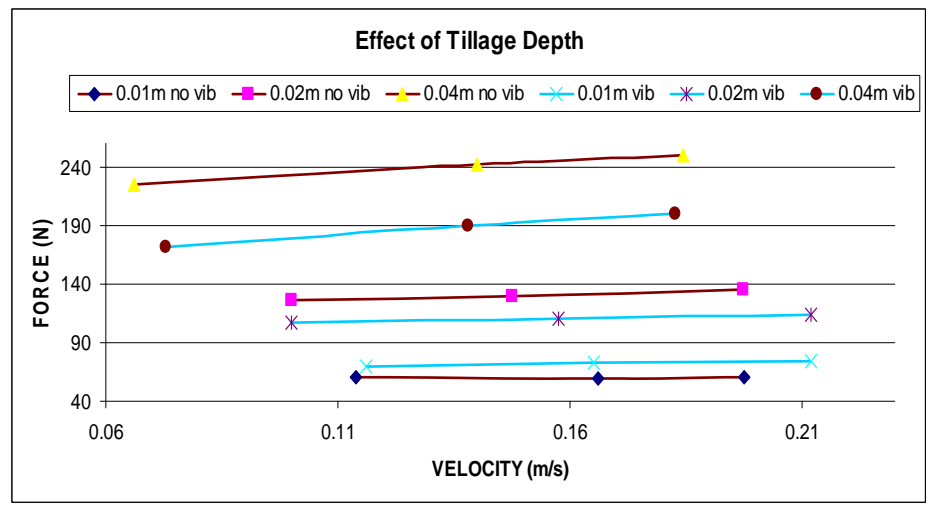

Fig. 13 Influence of tillage depth on draft force with and without vibratory tillage

\section{Effect of Soil Type}

The draft force is slightly lower with soil 2 due to the lower density of the soil, figure (14). Introducing vibration however, considerably decreases the draft force on either types of soil.

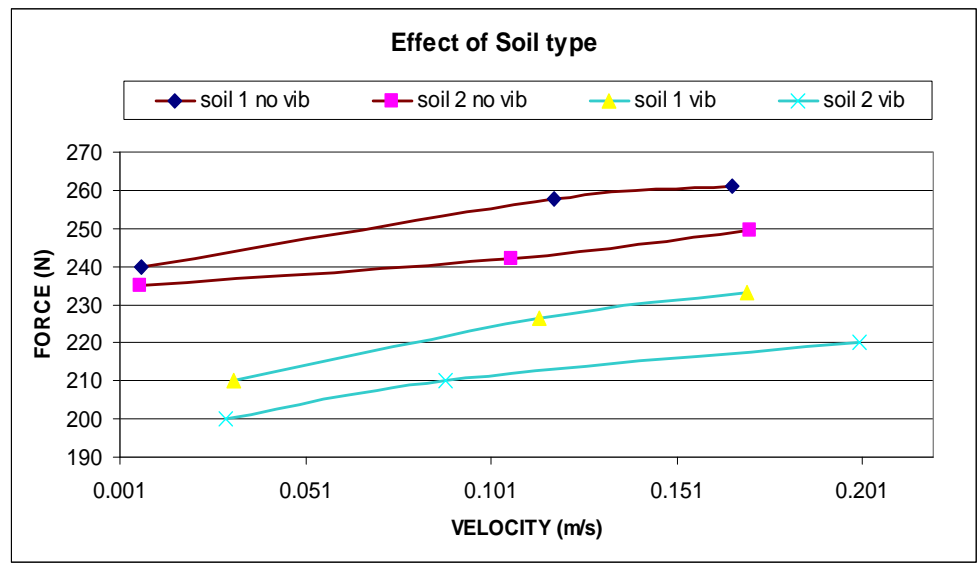

Fig. 14 Influence of soil type on draft force with and without vibratory tillage. 


\section{Effect of Blade Angle}

Figure (15) shows that the draft force increases with the blade angle at all operating conditions. This is more apparent in cases of vibration.

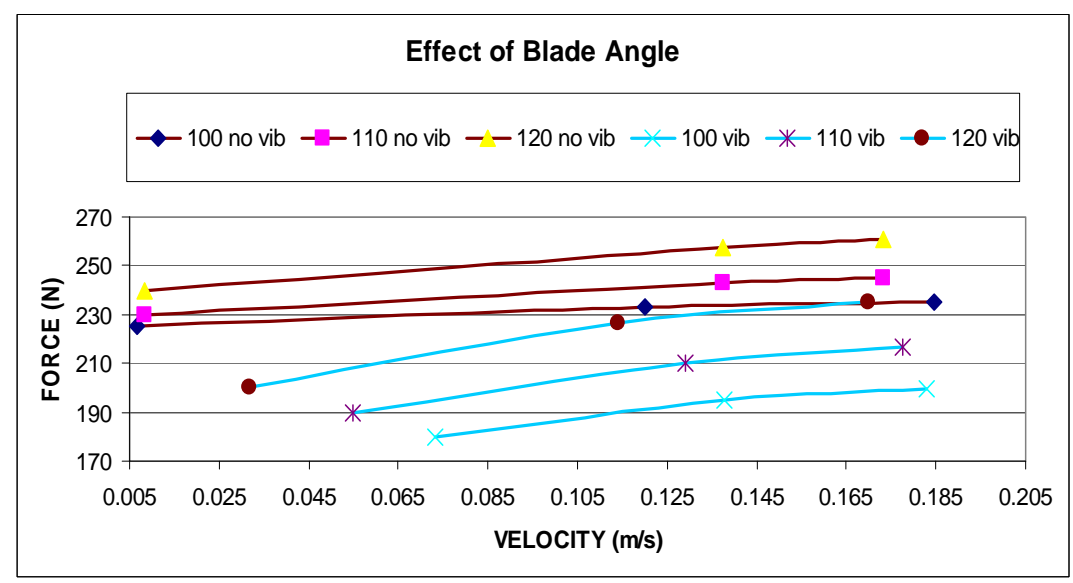

Fig. 15 Influence of blade angle on draft force with and without vibratory tillage.

\section{Influence of Vibration Parameters (Frequency and Amplitude) on Draft Force of Vibratory Tillage}

\section{a. Effect of Amplitude}

The relation between tillage vibration amplitude and draft force is shown in figure (16). An inverse proportionality at all operating conditions may be observed.

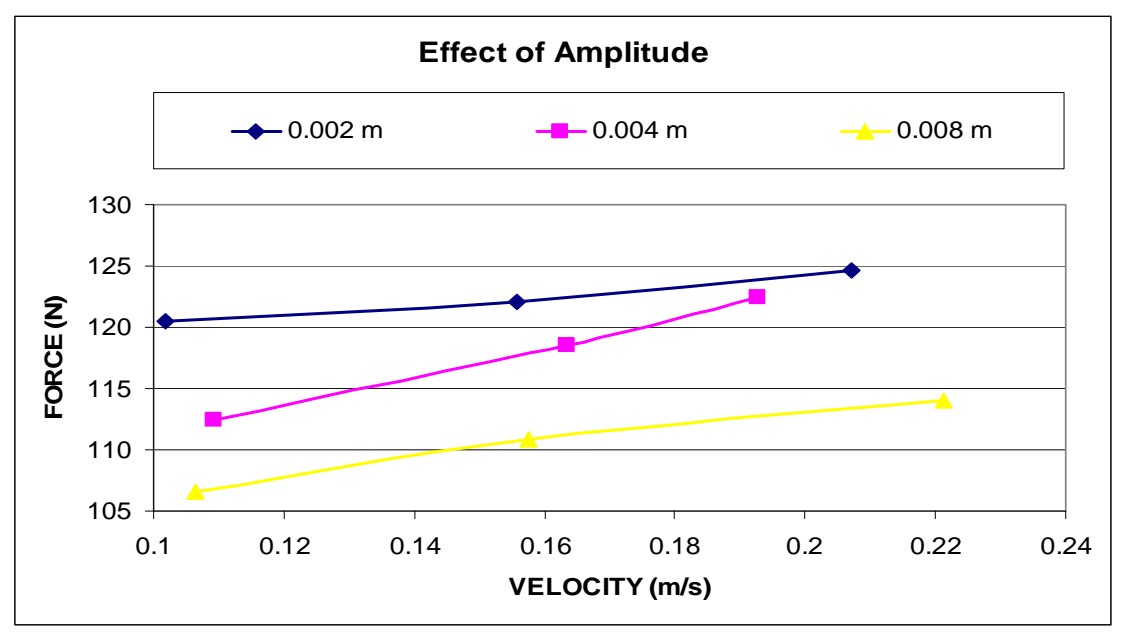

Fig. 16 Influence of amplitude on draft force. 


\section{b. Effect of Frequency}

Figure (17) shows the relation between the vibration frequency and the draft force. At all operating conditions, an inverse proportionality is observed.

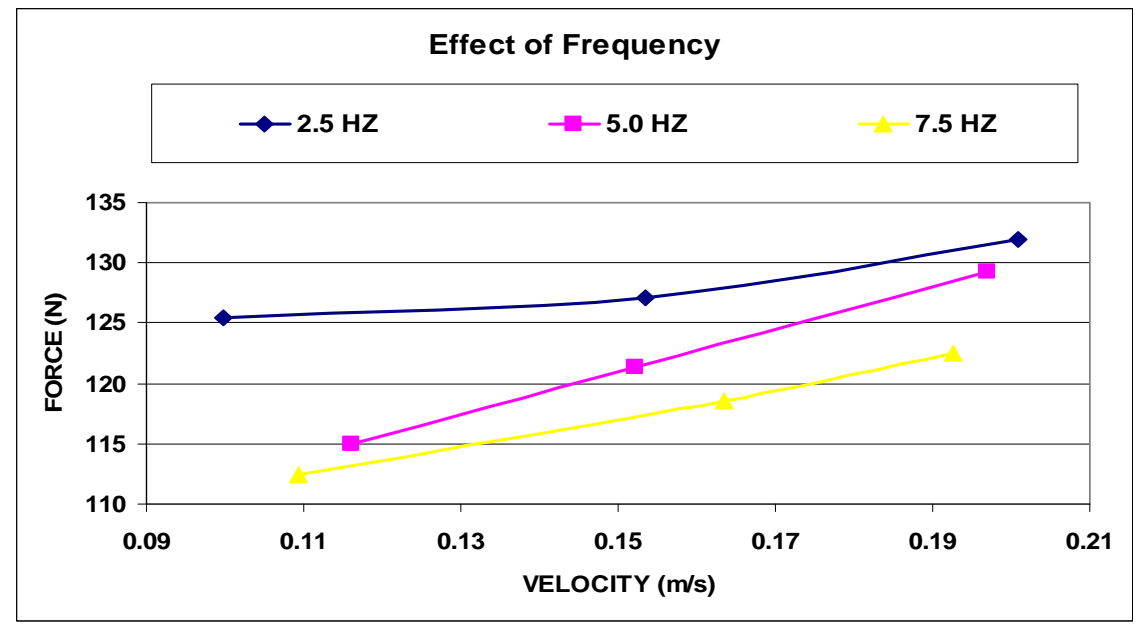

Fig. 17 Influence of frequency on draft force.

\section{Conclusions}

The experimental investigation conducted proved that tillage depth, tillage velocity and blade angle have direct proportional effects on the tillage resistance force. The introduction of tillage vibration leads to a considerable decrease in the tillage force. This could result in overcoming the soil resistance at conditions causing overloading of the non-vibrating system. The influence of vibration becomes more apparent as the tillage depth increases from 0.02 to $0.04 \mathrm{~m}$. On the other hand, the effect is negligible and may become even negative at the shallow depth of $0.01 \mathrm{~m}$. Increasing the vibration amplitude and frequency proportionally decreases the tillage resistance force. The authors summarize their conclusions as follows:

1. The vibratory motion of the tillage blade significantly reduces the tillage force from 10 $\%$ to $20 \%$ especially at tillage depths higher than $0.02 \mathrm{~m}$. This is most apparent at the tillage depth of $0.04 \mathrm{~m}$ when the driving mechanism can overcome the soil resistance only with blade vibration activated.

2. At shallow tillage depth $(0.01 \mathrm{~m})$, blade vibration has a negative effect on tillage (nearly $25 \%$ increase in the tillage force). This is attributed to the low soil resistance compared to the force needed to overcome the inertia forces of the vibrating masses.

3. Force reduction is directly proportional to the velocity ratio (mean forward speed of the blade due to vibration divided by the carriage speed). This ratio in practice must be higher than unity for the blade vibration to have the desired effect of reducing the tillage force. The force reduction is duplicated from $30 \mathrm{~N}$ to $60 \mathrm{~N}$ when velocity ratio is increased from 1 to 2 at tillage depth $0.04 \mathrm{~mm}$.

4. The tillage velocity has direct and proportional effects on the resistance force. The latter increases nearly 1, 3 and 6\% when the velocity is increased 50, 100 and $200 \%$ respectively. 
5. The angle of tillage has direct and proportional effects on the tillage resistance force. The increase in the latter is nearly 3 and $10 \%$ at tillage angles of $110^{\circ}$ and $120^{\circ}$ respectively compared to the force at $100^{\circ}$ tillage angle.

6. The amplitude of tine vibration has inverse and proportional effects on the tillage resistance force. The latter decreases nearly 4, 6 and 10\% with fixed frequency and amplitudes 2, 4 and $8 \mathrm{~mm}$ respectively compared to the force measured with no vibration.

7. The frequency of tine vibration has inverse and proportional effects on the tillage resistance force. The latter decreases about 13,18 and $28 \%$ at the same amplitude and frequencies $2.5,5$ and $7.5 \mathrm{~Hz}$ respectively compared to the force measured with no vibration.

\section{References}

[1] J. YOW and J. U SMITH," Sinusoidal vibratory tillage ", Journal of Terramechanies, Vol. 13, No. 4, pp. 21-226, 1976.

[2] M. SPEKTOR and M. KATZ," Experimental study of frontal resistance force in soil cutting", Journal of Terramechanics, Vol. 22, No. 3, pp. 127-133, 1985.

[3] T. NIYAMAPA and V. M. SALOKHE," Laboratory investigations into soil failure under vibratory tillage tools", Journal of Terramechanics, Vol. 30, No. 6, pp. 395403, 1993.

[4] T. NIYAMAPA A, V.M. SALOKHE," Force and pressure distribution under vibratory tillage tool", Journal of Terramechanics Vol. 37, pp. 139-150, 2000.

[5] TANYA NIYAMAPA A, V.M. SALOKHE," Soil disturbance and force mechanics of vibrating tillage tool", Journal of Terramechanics Vol. 37, pp. 151-166, 2000.

[6] MOOTAZ ABO-ELNOR, R. HAMILTON, J.T. Boyle "3D dynamic analysis of soil-tool interaction using the finite element method", Journal of Terramechanics, Vol.40 pp.51-62, 2003.

[7] T. MURO, D.T. TRAN," Regression analysis of the characteristics of vibro-cutting blade for tuffaceous rock", Journal of Terramechanics Vol. 40, pp.191-219, 2004.

[8] Canadian Foundation Engineering Manual 3rd edition 1992. 